\title{
Enhancement of the Binding of O-Ethyl O-p-Nitrophenyl Phenylphosphonate (EPNoxon) to Microsomal Carboxylesterase by NAD in vitro
}

\author{
Seiyu SUGIYAMA, Masakiyo HOSOKAWA, Takashi IGARASHI, \\ Koichi UENO, Tetsuo SATOH* and Haruo KITAGAWA \\ Laboratory of Biochemical Pharmacology and Biotoxicology, \\ Department of Drug Evaluation and Toxicologica! Sciences, \\ Faculty of Pharmaceutical Scierices, Chiba University. \\ 1-33 Yayoi-cho, Chiba 260. Japan
}

Accepted September 25, 1984

\begin{abstract}
Inhibition of rat liver microsomal carboxylesterase(CEase) by O-ethyl O-pnitrophenyl phenylphosphonothioate (EPN) and binding of EPN oxygen analog to microsomal CEase were enhanced by addition of NAD or NADP. This was more prominent in addition of NAD than NADP. No potentiation of anti-CEase action of EPN by NAD was seen when pure esterase (E.C. 3.1.1.1) instead of liver microsomes was used as an enzyme source. This effect of NAD in microsomal CEase was significantly decreased when $\mathrm{N}$-ethylmaleimide or $\mathrm{p}$-chloromercuribenzoic acid was added. From these findings, it is strongly suggested that NADmediated potentiation of the anti-CEase action of EPN might be attributed to the increase in formation of NADH from NAD by microsomal dehydrogenase(s) containing a sulfhydryl group, leading to a subsequent increase in formation of the EPN oxygen analog from EPN, and in turn, CEase inhibition was enhanced.
\end{abstract}

Our previous papers revealed that addition of NAD to the incubation mixture containing rat liver microsomes and organophosphorothioates such as EPN and parathion can enhance the anti-carboxylesterase (CEase) action of these insecticides, but to a lesser extent in acetylcholinesterase (1). This phenomenon has been referred to as the "NAD-effect" in this study. Furthermore, the NAD-effect was not seen with the respective organophosphates and was found only when either $\beta$-NAD or 3 -acetylpyridine adenine dinucleotide among five derivatives of NAD is added. This was closely related to the function of microsomal dehydrogenase(s).

The present study was undertaken to further investigate the characteristics of microsomal dehydrogenase(s) responsible for occurrence

\footnotetext{
* Present address: Department of Pharmacology. Tokyo College of Pharmacy, 1432-1 Horinouchi. Hachioji, Tokyo 192-03, Japan
}

of the NAD-effect and the relationship between covalent binding of the EPN oxygen analog to microsomal CEase and the enzyme inhibition.

\section{Materials and Methods}

Animals: Adult male rats of the Wistar strain, weighing $200-230 \mathrm{~g}$. were used. They were maintained on standard laboratory chow (Oriental Yeast Co., MF) and tap water ad libitum under the condition of constant room temperature $\left(23-25^{\circ} \mathrm{C}\right)$ for at least one week before use.

Preparation of liver microsomes: The rats were sacrificed by decapitation, and the livers were immediately removed. Perfusion with $1.15 \% \mathrm{KCl}$ was carried out to remove the blood after weighing the liver. Then, two volumes of ice-cold $1.15 \% \mathrm{KCl}$ was added to give a $33 \%(w / v)$ homogenate. The homogenate was centrifuged at $9,000 \times \mathrm{g}$ for $20 \mathrm{~min}$, followed by recentrifugation of the 
supernatant at $105,000 \times \mathrm{g}$ for $60 \mathrm{~min}$. The resulting pellets were washed once with icecold $1.15 \% \mathrm{KCl}$

Enzyme assay: CEase activity was determined using the colorimetric assay procedure based on conversion of isocarboxazid to benzylhydrazine $(\mathrm{BZH})$ as described previously $(1,2)$.

Determination of binding of labelled-EPN to liver microsomal protein: After incubation of phenyl- ${ }^{4} \mathrm{C}-\mathrm{EPN}$ with $\mathrm{NAD}(\mathrm{P})$ and liver microsomes for $10 \mathrm{~min}$, reaction was terminated by the addition of $15 \%$ metaphosphoric acid solution, and the precipitated microsomal proteins were separated by centrifugation at $3.000 \mathrm{rpm}$ for $10 \mathrm{~min}$. The supernatant fraction was removed and the pellet was washed vigorously with $15 \%$ metaphosphoric acid solution. Then, methanol was added to wash the pellet several times until no further radioactivity was detected in the supernatant. The final pellet was redissolved in $1 \mathrm{~N}$ sodium hydroxide solution at $80^{\circ} \mathrm{C}$. The ${ }^{14} \mathrm{C}$-radioactivity was measured by adding $10 \mathrm{ml}$ aliquots of AQUASOL and counted by using a liquid scintillation counter (Beckman, model LS-100C), correcting for background and quenching.

The protein concentration of the liver microsomes was determined according to the method of Lowry et al. (3) using crystalline bovine serum albumin as a standard.

\section{Results}

Effects of NAD on EPN-induced inhibition of rat liver microsomal CEase and pure esterase: In order to determine the requirement of microsomal factor(s) responsible for potentiation of EPN-induced inhibition of CEase by NAD (NAD-effect), microsomal CEase was compared to that with pure esterase (E.C. 3.1.1.1). As shown in Table 1, no NAD-effect was seen when pure esterase was used.

Effects of NAD and NADP on the EPNinduced inhibition of CEase and the binding of ${ }^{14} \mathrm{C}-\mathrm{EPN}$ to microsomal protein: As shown in Fig. 1. EPN-induced inhibition of microsomal CEase was potentiated by addition of either NAD and NADP. A sigmoidal curve was seen in the CEase activity as a function of NAD concentrations ranging from $1 \times 10^{-6}$ $\mathrm{M}$ to $1 \times 10^{-4} \mathrm{M}$. On the other hand, the binding of ${ }^{14} \mathrm{C}$-radioactivity to microsomal protein was increased in parallel with concentrations of NAD, and a lesser extent of the NAD-effect was observed by addition of NADP instead of NAD.

Effect of sulfhydryl reagents on NADeffect: As shown in Table 2, no NAD-effect was seen in presence of $\mathrm{N}$-ethylmaleimide (NEM) (1 $\mathrm{mM})$ or p-chloromercuribenzoic acid (PCMB) (0.1 mM), but not when iodoacetic acid (IAA) (1 mM) was added.

Effects of pretreatment of liver microsomes with EPN and sulfhydryl reagents on NADeffect: Three inhibitors were used to clarify the possibility that sulfhydryl group(s) in liver microsomes might be involved in the NAD-effect. The incubation mixture consisting of $3 \mathrm{mg}$ protein of microsomal pellet, $1 \mathrm{mM}$ of EPN and $3 \mathrm{mM}$ of sulfhydryl reagents was preincubated at $37^{\circ} \mathrm{C}$ for $10 \mathrm{~min}$. Then, dialysis was done to remove surplus EPN and sulfhydryl reagents at $4{ }^{\circ} \mathrm{C}$ for $24 \mathrm{hr}$ in $1.15 \% \mathrm{KCl}$. Pure esterase (E.C. 3.1.1.1). $0.125 U$, was added to the incubation

Table 1. Effects of NAD on EPN-induced inhibition of rat liver microsomal carboxylesterase and pure esterase in vitro

$\begin{array}{lcc}\text { Addition } & \text { CEase activity } & \text { Pure esterase activity } \\ \text { None } & 65.7 \pm 2.8 & 122.1 \pm 6.3 \\ \text { EPN } & 61.0 \pm 3.3 & 100.1 \pm 4.1 \\ \text { EPN + NAD } & 9.2 \pm 4.6^{*} & 101.0 \pm 4.6\end{array}$

Activities of microsomal carboxylesterase (CEase) and pure esterase (from hog liver microsomes, E.C. 3.1.1.1) were shown as rimoles BZH formed $/ \mathrm{mg}$ protein $/ 30 \mathrm{~min}$. The concentrations of EPN and NAD were $1 \times 10^{-5} \mathrm{M}$ and $5 \times 10^{-5} \mathrm{M}$, respectively. Each value is the mean $\pm S . E$. from three experiments. ${ }^{*} P<0.01$ : statistically significant difference from the EPN addition group. 


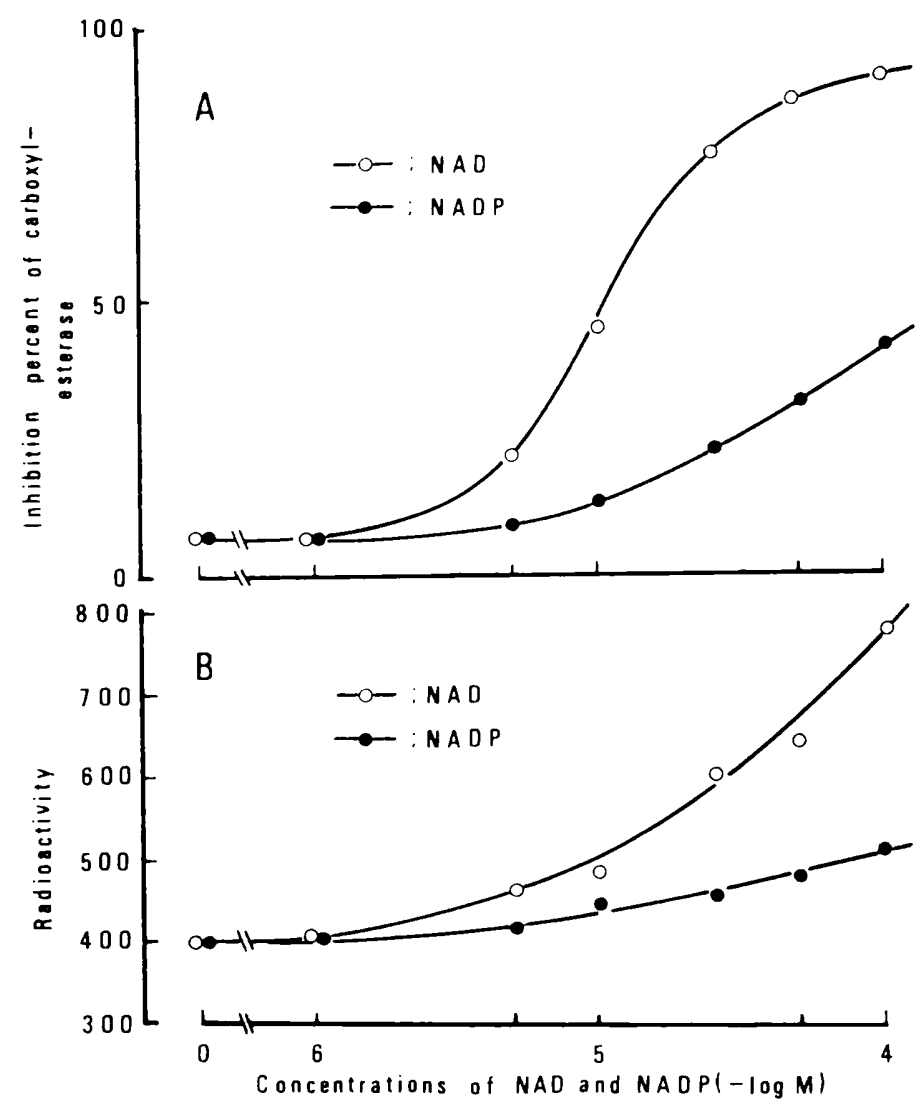

Fig. 1. Effects of NAD and NADP on the EPN-induced inhibition of carboxylesterase and binding of ${ }^{14} \mathrm{C}$-EPN to microsomal protein. Inhibition percent of carboxylesterase activity and amount of ${ }^{14} \mathrm{C}$ EPN bound to microsomal protein (pmoles ${ }^{14} \mathrm{C}$-bound/mg protein/10 min) are shown in $\mathrm{A}$ and $\mathrm{B}$ of the figure. The concentration of EPN used was $1 \times 10^{-5} \mathrm{M}$. Each point is the mean of three experiments. -O-: NAD, - - : NADP.

Table 2. Effects of sulfhydryl reagents on the NAD-mediated potentiation of anti-carboxylesterase action of EPN in vitro

\begin{tabular}{|c|c|c|c|c|c|c|c|}
\hline \multirow{3}{*}{ Addition } & \multirow{3}{*}{ None } & \multicolumn{6}{|c|}{ Sulfhydryl reagent } \\
\hline & & \multicolumn{2}{|c|}{ NEM } & \multicolumn{2}{|c|}{ PCMB } & \multicolumn{2}{|c|}{ IAA } \\
\hline & & $0.1 \mathrm{mM}$ & $1 \mathrm{mM}$ & $0.01 \mathrm{mM}$ & $\begin{array}{c}0.1 \mathrm{mM} \\
-\end{array}$ & $0.1 \mathrm{mM}$ & $1 \mathrm{mM}$ \\
\hline Control & $58.0 \pm 3.5$ & $53.2 \pm 3.3$ & $40.6 \pm 1.7$ & $57.4 \pm 5.0$ & $52.7 \pm 4.7$ & $54.6 \pm 2.7$ & $51.3 \pm 3.5$ \\
\hline EPN & $52.2 \pm 3.4$ & $49.1 \pm 3.2$ & $38.6 \pm 1.4$ & $52.3 \pm 4.7$ & $47.9 \pm 4.7$ & $49.8 \pm 3.0$ & $46.5 \pm 2.8$ \\
\hline$E P N+N A D$ & $3.5 \pm 0.5^{*}$ & $3.8 \pm 0.4^{*}$ & $34.2 \pm 1.7$ & $6.9 \pm 2.7^{*}$ & $45.6 \pm 5.4$ & $3.3 \pm 0.5^{*}$ & $3.3 \pm 0.6^{*}$ \\
\hline
\end{tabular}

Carboxylesterase áctivity was shown as nmoles BZH formed/mg protein $/ 30 \mathrm{~min}$. The concentrations of EPN and NAD used were $1 \times 10^{-5} \mathrm{M}$ and $5 \times 10^{-5} \mathrm{M}$, respectively. Each value is the mean \pm S.E. from $3-5$ experiments. NEM: N-ethylmaleimide. PCMB: p-chloromercurbenzoic acid. IAA: iodoacetic acid. "P<0.01: statistically significant difference from the EPN alone group. 
Table 3. Effects of pretreatment of liver microsomes with EPN and sulfhydryl reagents on the NADeffect

Pretreatment

$\begin{array}{ll} & \text { Control } \\ \text { EPN } & 100.0 \\ \text { EPN+NEM } & 100.0 \\ \text { EPN+PCMB } & 100.0 \\ \text { EPN+IAA } & 100.0\end{array}$

Carboxylesterase activity ( $\%$ of control)

EPN

$95.6 \pm 5.6$
$92.8 \pm 13.3$
$92.2 \pm 27.3$
$96.0 \pm 5.9$

$E P N+N A D$

$35.0 \pm 11.2^{* *}$

$93.4 \pm 13.3$

$92.9 \pm 26.6$

$71.1 \pm 8.9^{*}$

The microsomes were pretreated with EPN and sulfhydryl reagents for $10 \mathrm{~min}$ at $37^{\circ} \mathrm{C}$. The concentrations of EPN and sulfhydryl reagents used in the pretreatment were $1 \mathrm{mM}$ and $3 \mathrm{mM}$, respectively. After dialysis, $0.125 \cup$ of pure esterase (E.C.3.1.1.1) was added in the incubation mixture of these experiments. The concentrations of EPN and NAD used in the assay mixture were $1 \times 10^{-5} \mathrm{M}$ and $5 \times 10^{-5} \mathrm{M}$, respectively. Each value is the mean $\pm S$. E. from three experiments. ${ }^{*} P<0.05$ and ${ }^{*} P<0.01$ : statistically significant difference from each control group.

mixture for CEase assay in this study. As shown in Table 3, the NAD-effect still remained when IAA-pretreated microsomes were used, but not with NEM- or PCMBpretreatment.

Effects of sulfhydryl reagents on the NADeffect and binding of ${ }^{14} \mathrm{C}$-EPN to microsomai protein: Based on the fact that the NAD effect was not seen by addition of NEM or $\mathrm{PCMB}$, we investigated the effect of $1 \mathrm{mM}$ of sulfhydryl reagents on the binding of ${ }^{14} \mathrm{C}$ EPN to microsomal protein. As shown in Fig. 2, the potentiation of EPN-induced inhibition of CEase by NAD and the increase in binding of ${ }^{14} \mathrm{C}$-radioactivity to microsomal protein by NAD were observed in the absence of sulfhydryl reagents. On the other hand, addition of NEM or PCMB to the incubation mixture resulted in no difference in the binding of ${ }^{14} \mathrm{C}$-radioactivity to microsomal protein between in the presence or absence of NAD. This result showed a good correlation with the effects of NEM or PCMB on CEase activity. In the case of IAA, however, a significant inhibition of CEase activity and increase in the binding of ${ }^{14} \mathrm{C}$-radioactivity to microsomal protein were observed.

\section{Discussion}

In the previous papers, we reported that addition of NAD to the incubation mixture containing rat liver microsomes and EPN enhanced inhibition of microsomal CEase by EPN (1). In addition, the fact that no NAD-effect was observed when pure
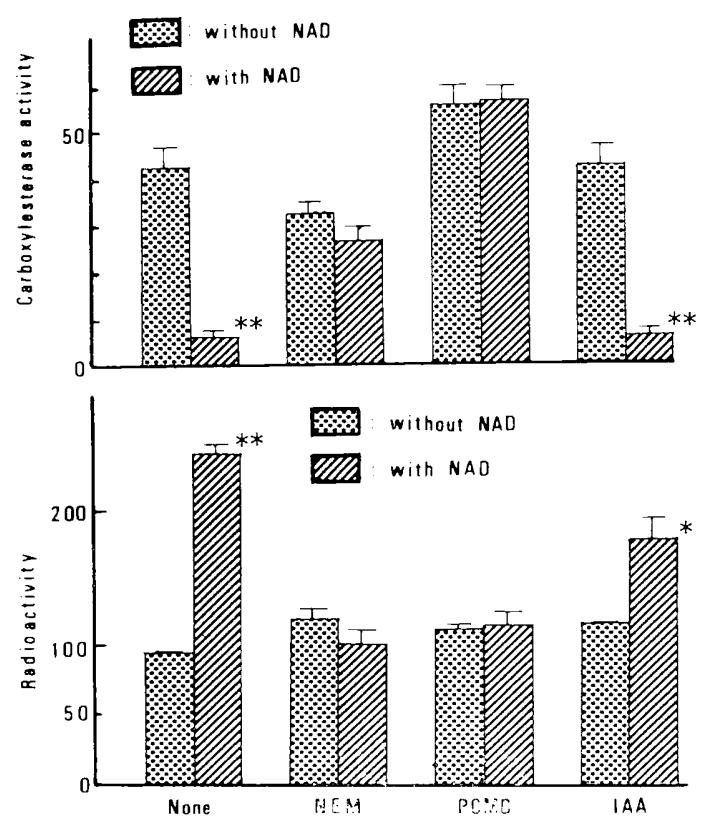

Fig. 2. Effects of sulfhydryl reagents on the NADmediated potentiation of anti-carboxylesterase action of EPN and binding of ${ }^{14} \mathrm{C}$-EPN to microsomal protein. Carboxylesterase activity and amount of ${ }^{14} \mathrm{C}$-EPN bound to microsomal protein were shown as nmoles BZH formed/mg protein $/ 30 \mathrm{~min}$ and pmoles ${ }^{14} \mathrm{C}$-bound/mg protein/10 min, respective!y. The concentrations of EPN, NAD and sulfhydryl reagents used were $1 \times 10^{-5} \mathrm{M}, 5 \times 10^{-5} \mathrm{M}$ and $1 \mathrm{mM}$. respectively. Each column is the mean $\pm S$.E. from three experiments. ${ }^{*} \mathrm{P}<0.05$ and ${ }^{*} \mathrm{P}<0.01$ : showed a statistically significant difference from the none added group. 
Table 4. Effects of NAD on the enzymatic formation of EPNoxon from EPN and carboxylesterase activity

\begin{tabular}{lccc}
\hline Addition & $\begin{array}{c}\text { EPNoxon } \\
(\mathrm{M})\end{array}$ & $\begin{array}{c}\% \\
\text { (EPNoxon/EPN) }\end{array}$ & $\begin{array}{c}\text { Carboxylesterase } \\
\text { (\% of control) }\end{array}$ \\
None & - & - & 100.0 \\
EPN & N.D. & - & 85.9 \\
EPN + NAD & $3.5 \times 10^{-7}$ & 2.3 & 13.3 \\
EPN+NAD+PMSF+EDTA & $4.7 \times 10^{-7}$ & 3.1 & - \\
\hline
\end{tabular}

The concentrations of EPN added were $1.5 \times 10^{-5} \mathrm{M} i n 10 \mathrm{ml}$ of incubation mixture for the EPNoxon assay and $1 \times 10^{-5} \mathrm{M}$ in $1.5 \mathrm{ml}$ of incubation mixture for the carboxylesterase assey, respectively. The concentrations of NAD used were $7.5 \times 10^{-5} \mathrm{M}$ for the EPNoxon assay and $5 \times 10^{-5} \mathrm{M}$ for the carboxylesterase assay, respectively. PMSF alıd EDTA added were $1 \mathrm{mM}$ and $4.5 \times 10^{-5} \mathrm{M}$, respectively. N.D.: less than $0.5 \times 10^{-7} \mathrm{M}$. Each value is the mean of two experiments. EPNoxon was determined by the GC-MS method.

esterase (E.C. 3.1.1.1) instead of liver microsomes was used, suggested that unknown factor(s), presumably dehydrogenase (s), present in liver microsomes was required to show a potentiation of the anti-CEase action of EPN by NAD.

The present paper revealed that binding of ${ }^{14} \mathrm{C}$-EPN to liver microsomal protein was also markedly increased when NAD was added to the incubation mixture. Further, potentiation of the anti-CEase action of EPN and increase of binding of ${ }^{14} \mathrm{C}$-radioactivity to microsomal protein by NAD were both blocked by addition of sulfhydryl reagents. Therefore, it is likely that EPN added might be oxidized to EPNoxon by liver microsomal dehydrogenase(s) possessing sulfhydryl groups which require mainly $\mathrm{NADH}$ as a cofactor; then the EPNoxon formed was bound to liver microsomal CEase. Our preliminary study revealed that the enzymatic formation of EPNoxon was seen when NAD was added to the incubation mixture for CEase assay (Table 4). Unlike many other foreign compounds, several papers report that NADH is 40-80 percent as effective as $\mathrm{NADPH}$ in the oxidative reaction by cytochrome P-450-coupled monooxygenase (46 ) or essentially the same extent was observed by others (7-9). Kulkarni and Hodgson described that the activities reported for NAD added to a reaction mixture containing crude homogenate are due to NADH generated by dehydrogenases or to NADPH resulting from $\mathrm{NADH}$ by the action of transhydrogenase. Although some of the most puzzling obser- vations mentioned above could be related to the nucleotide concentrations used, others can not be satisfactorily explained (10). In conclusion, data in this paper were understood to show that formation of EPNoxon was catalyzed by cytochrome P-450-coupled monooxygenase with NADH which was formed irom NAD by microsomal membranebound dehydrogenase(s). Further studies are now in progress.

Acknowledgment: We are grateful to Miss. Mari Takamiya for excellent technical assistance.

\section{References}

1 Satoh, T., Sugiyama, S. and Kitagawa, H.: Potentiation of ethyl para-nitrophenyl pheny!phosphonothioate (EPN)-induced inhibition of liver microsomal carboxylesterase by NAD in vitro in rats. Res. Commun. Chem. Pathol. Pharmacol. 26, 547-562 (1979)

2 Satoh, T. and Moroi, K.: A simple and sensitive colorimetric assay of benzylhydrazine. Anal. Chim. Acta 51, 449-454 (1970)

3 Lowry, H., Rosebrough, N.J., Farr, A.L. and Randall, R.J.: Protein mesurement with the Folin phenol reagent. J. Biol. Chem. 193, 265-275 (1951)

4 Nakatsugawa, T., Ishida, M. and Dahm, P.A.: Microsomal epoxidation of cyclodiene insecticides. Biochem. Pharmacol. 14, 1853-1865 (1965)

5 Morello, A., Vandanis, A. and Spencer, E.Y.: Comparative metabolism of two vinyl phosphorothioate isomers (thione phosdrin) by the mouse and the fly. Biochem. Pharmacol. 17. 1795-1802. (1968)

6 Shishido, T., Usui, K. and Fukami, J.: Oxidative 
metabolism of diazinon by microsomes from rat liver and cockroach fat body. Pesticide Biochem. Physiol. 2, 27-38 (1972)

7 O'Brien, R.D.: Activation of phosphorothioate by liver microsomes. Nature (Lond.) 183, 121-122 (1959)

8 Casida, J.E.: Specificity of substituted pheriy! phosphorus compounds for esterase inhibition in mice. Biochem. Pharmacol. 5, 332-342 (1961)

9 Hitchcock, M. and Murphy, S.D.: Activation of parathion and guthion by mammalian, avian and piscine liver homogenates and cell fractions. Toxicol. Appl. Pharmacol. 19, 37-45 (1971)

10 Kulkarni, A.P. and Hodgson, E.: Metabolism of insecticides by mixed function oxidase systems. Pharmacol. Ther. 8, 379-475 (1980) 